\title{
Nutritional Evaluation by Nurses and Physical Recovery of Malnourished Patients after Esophagectomy
}

\author{
Tomoko Uno $^{1^{*}}$ (D), Sadako Yoshimura ${ }^{2}$ \\ ${ }^{1}$ Department of Nursing, School of Health Sciences, Sapporo Medical University, Sapporo, Japan \\ ${ }^{2}$ Faculty of Health Sciences, Hokkaido University, Sapporo, Japan \\ Email: *tuno@sapmed.ac.jp
}

How to cite this paper: Uno, T. and Yoshimura, S. (2022) Nutritional Evaluation by Nurses and Physical Recovery of Malnourished Patients after Esophagectomy. Open Journal of Nursing, 12, 12-24. https://doi.org/10.4236/ojn.2022.121002

Received: December 24, 2021

Accepted: January 23, 2022

Published: January 26, 2022

Copyright (๑) 2022 by author(s) and Scientific Research Publishing Inc. This work is licensed under the Creative Commons Attribution International License (CC BY 4.0).

http://creativecommons.org/licenses/by/4.0/ (c) (i) Open Access

\begin{abstract}
Following an esophagectomy, nurses' patient nutrition observations are important for physical recovery and quality of life. The study proposed to identify the factors associated with physical recovery among esophageal cancer patients after surgery based on nurses' observations and nutritional evaluations. Data were collected from the nursing records of 21 esophagectomy patients. The data included patients' rate of weight loss, body mass index (BMI), energy intake, and postoperative complications. Patients were divided into two groups according to their weight loss rate: $<8 \%$ and $\geq 8 \%$. Patient outcomes were compared between the two groups. There was no difference in average BMI before or after surgery between the two groups. There was no difference in albumin levels during hospitalization; however, after esophagectomy, energy intake at discharge was insufficient in both groups. The $\geq 8 \%$ weight loss may be facilitated, or at least confounded, by the presence of recurrent nerve paralysis and aspiration pneumonia. Thus, the nursing records typically identified the need to check for recurrent laryngeal nerve palsy and aspiration pneumonia in conjunction with nutritional assessment to enhance patients' physical recovery. When weight loss was significant, nurses provided oral intake support with the NST, and patients maintained oral intake levels similar to the group with weight loss under $8 \%$. In order to better support physical recovery among malnourished, post esophagectomy patients, nurses need to monitor for signs of recurrent nerve palsy and aspiration pneumonia in addition to nutritional intake.
\end{abstract}

\section{Keywords}

Esophagectomy, Esophageal Cancer, Perioperative Nursing, Nutritional Assessment, Aspiration Pneumonia 


\section{Introduction}

According to The International Agency for Research on Cancer, esophageal cancer is the tenth most common malignancy and the seventh leading cause of cancer death in Japan. In 2008, there were an estimated 17,497 new cases and 11,746 deaths. The estimated age-adjusted incidence rate (standardized for the world population) in 2008 was 5.7 per 100,000 population. Data from the Center for Cancer Control and Information Services showed that the age-adjusted incidence rate (per 100,000 population) increased among Japanese men from 8.3 to 11.7 during 1975-2006, but barely changed among Japanese women, who had a lower incidence rate of approximately 1.5 [1]. From 1950 until 2010, the annual death rate continued to increase among Japanese men but did not change significantly among Japanese women [2].

Since 2005, fast-track surgery and enhanced recovery after surgery (ERAS) programs [3] have promoted faster recovery for esophagectomy patients. For example, perioperative nutrition management targets the preoperative, intraoperative, and postoperative care. One study showed it can reduce postoperative complications and the length of hospital stays [4], lowering treatment and patient costs.

Postoperative patients undergoing esophagectomy may experience recurrent nerve palsy and dysphagia due to surgical procedures such as lymph node dissection. In addition, after the esophagectomy, the gastric tube volume decreases, as the gastric tube is used for reconstructing the esophagus, and the reduced storage function leads to decreased food intake per dose. Consequently, patients' nutritional status is likely to deteriorate after esophagectomy [5]. Oral intake is considerably diminished after surgery because of mechanical and functional gastrointestinal tract changes that cause swallowing disorders, early satiety, and postprandial dumping syndrome [6]. Nutritional management is therefore crucial for surgical outcomes and postoperative quality of life (QOL).

After surgery, higher severity grades of common complications (i.e., pneumonia, anastomotic leakage, chyle leakage, and cardiac issues) are associated with increased hospital costs and length of stay [7]. Nurses who observe these symptoms immediately report it to the attending physician. In Japan, if a nurse assesses a patient as at high risk of malnutrition after surgery, the attending physician can recommend nutritional support. By monitoring nutritional intake, nurses promote patients' physical recovery after surgery, as maintaining nutritional status leads to an improvement in QOL [8].

Some patients treated surgically for esophageal cancer require supplemental nutritional management using enteral and parenteral nutrition to fulfill their needs perioperative. However, in order to shorten postoperative hospital stays, patients are often discharged after fulfilling nutritional requirements via supplemental methods despite displaying inappropriate oral intake [9]. General algorithms for nutrition administration recommend that oral intake (i.e., the physiological food administration route) be re-established as soon as possible and 
that it should take priority over enteral and parenteral nutrition [10] [11]. Several studies have reported that esophageal cancer surgery patients resumed oral feeding at postoperative day 1 [12] [13], and the importance of promoting oral intake is increasingly being considered. The cephalic phase responses can explain the benefits of oral intake, as they prepare the gastrointestinal tract for digestion and absorption [14] [15]. Therefore, our aim was to examine nursing practices to reduce malnutrition by focusing on observation and nutritional evaluation of patients after an esophagectomy.

In Japan, lymph node dissection in esophageal cancer is often performed in the neck, chest, and abdomen. These operations cover a wide area and are therefore very invasive, with common postoperative complications such as suture failure and pneumonia. In postoperative patients, dysphagia is an important complication, $30 \%$ of patients experienced food aspiration, and $25 \%$ developed aspiration pneumonia [16]. Frequent postoperative difficulties include dysphagia (50\%), decreased physical strength (39.5\%), and oral intake reduced to half (55.3\%) or one-fourth (25.5\%) of their original level [17], suggested the importance of supporting oral intake. Postoperative nutritional parameters assessed by either weight change (as a percentage or absolute amount) or body mass index (BMI) were reported in most studies [18]. Weight loss is a significant issue for these patients. Clinical trials evaluating operative variables such as reconstruction route or gastric tube type (whole or narrow) showed no improvement regarding calorie intake or postoperative weight loss [19] [20]. Research demonstrated nutritional decline is common after an esophagectomy, with the greatest changes occurring in the first month after surgery when weight loss ranged from $5 \%$ to $8 \%$ [21] [22]. Nurses play a crucial role in observing oral intake and body weight to reduce malnutrition. They also determine the need for the nutrition support team (NST).

This study compared patients at high risk of dysphagia during the perioperative period of esophagectomy. This study proposed to identify the factors associated with physical recovery and malnutrition based on nurses' nutritional evaluation and observation after esophagectomy.

\section{Materials and Methods}

\subsection{Patients}

This study adopted a descriptive observational design. Participants were patients undergoing esophagectomy for esophageal cancer at Hokkaido University Hospital from April 2008 to March 2014, who were able to hold a sitting position without assistance following the procedure and who had started oral food intake 7 days after surgery. The following patients were excluded from the study:

- Patients with impaired consciousness.

- Patients undergoing an esophagectomy for the purpose of palliative surgery or bypass. 
- Patients whose oral intake after surgery started more than 7 days after surgery.

\subsection{Data Collection}

The following data, routinely recorded in nurse records as part of standard care, were extracted:

- Basic patient information: age, sex, height, body weight, diagnosis, details of surgery, number of days in hospital.

- Rate of weight loss based on body weight, body mass index (BMI), and adequacy of energy intake.

- Total serum albumin (before surgery, at discharge, and 7, 14, and 21 days after surgery).

- Dietary and caloric intake details by intake route (before surgery, at discharge, and 7, 14, and 21 days after surgery), with postoperative diet specifying the contents of the meal provided.

- Presence of postoperative complications (swallowing impairment, recurrent nerve palsy, aspiration pneumonia, reflux symptoms, obstruction, anastomotic leakage).

\subsection{Ethical Considerations}

This research was approved by the ethics committee of the Hokkaido University Hospital (approval number 010-0046), and proof of approval, based on appropriate regulations, was published on the homepage of this institution. Written informed consent was obtained from all the patients.

\subsection{Statistical Analyses}

The sample was divided into two groups according to weight loss rate: patients with weight loss $\geq 8 \%$ and patients with weight loss $<8 \%$. Objective data were compared between the two groups. The cutoff point was chosen based on previous research [23] that indicated weight loss rate at discharge was $8 \%$. The association between patient nutrition data and complications was assessed univariably with the chi-square test. Continuous variables were summarized using the mean and standard deviation (SD). The rate of weight loss was calculated using the formula [(pre-operative body weight-postoperative body weight)/pre-operative body weight $\times 100$ ]. The adequacy of energy intake was calculated by dividing the actual caloric intake by the required caloric intake, and the required caloric intake was calculated by multiplying the basal metabolism (estimated using the Harris-Benedict equation) by the activity index and the stress index. A group time repeated-measures ANOVA was conducted. In addition, a baseline adjusted ANCOVA comparing groups at discharge was used. Preoperative data were scored for 3 days after admission, and postoperative data were scored for 3 days before discharge. The statistical software JMP 14.2.0 was used, and a significance level of less than $5 \%$ was considered statistically significant. 


\section{Results}

\subsection{Hospitalization Process and Characteristics}

According to the inclusion and exclusion criteria, 47 patients were enrolled. Four patients were excluded because they experienced continuous difficulty with oral intake immediately after surgery, and 21 patients were excluded because of difficulty with oral intake combined with bilateral nerve palsy or worsening suture failure. After exclusions, data from 22 patients were analyzed in this study. All patients were men and had undergone esophagectomy through the retrosternal route or posterior mediastinal route.

There were 13 participants in the $<8 \%$ weight loss group and 9 in the $\geq 8 \%$ weight loss group. The data were pooled in the two groups. Nurses requested NST intervention for all the patients in the $\geq 8 \%$ weight loss group. Nurses did not request NST support for any patients in the in $<8 \%$ weight loss group. The $<8 \%$ weight loss group followed a diet according to their digestive function (foods that were easily sucked up by a straw). The diet of the $\geq 8 \%$ weight loss group included partial rice gruel, followed by a diet based on patients' swallowing function.

During hospitalization, all patients received oral care and respiratory rehabilitation from admission to surgery (i.e., a mean period of $5 \pm 2$ days), intubation in the ICU from post-surgery to the following day, and nursing care following artificial respiration removal on the second day post-surgery. In the $\geq 8 \%$ weight loss group, on day 3 post-surgery, a physiotherapist provided respiratory rehabilitation, and a speech therapist provided swallowing rehabilitation. From the seventh day onward, a registered dietician monitored oral intake and food provision. In the $<8 \%$ weight loss group, nurses assumed the role of speech therapists and registered dieticians. The patients in the $<8 \%$ weight loss group had an average age of $64.9 \pm 6$ years, and in the $\geq 8 \%$ weight loss group had an average age of $62.4 \pm 14$ years. The number of days spent in the hospital following surgery was $29 \pm 3$ days in the $<8 \%$ weight loss group, and $48 \pm 4$ days in the $\geq 8 \%$ weight loss group $(\mathrm{p}<0.05)$ (Table 1$)$. Compared with the $<8 \%$ weight loss group, the $\geq 8 \%$ weight loss group had a higher rate of recurrent nerve palsy and aspiration pneumonia $(\mathrm{p}<0.05)($ Table 2$)$.

Table 1. Clinical and demographic characteristics of study participants.

\begin{tabular}{ccc}
\hline & $\begin{array}{c}<8 \% \text { weight } \\
\text { loss group }\end{array}$ & $\begin{array}{c}\mathbf{8} \% \text { weight } \\
\text { loss group }\end{array}$ \\
\hline Age (years) & $64.9 \pm 6$ & $62.4 \pm 14$ \\
Hospital stays (days) & $40 \pm 14$ & $57 \pm 12^{*}$ \\
Postoperative days (days) & $29 \pm 3$ & $48 \pm 4^{*}$
\end{tabular}

Values given are mean \pm SD. ${ }^{*} \mathrm{p}<0.05$ (compare with Nurse Group value) in wilcoxon signed-rank test. 
Table 2. Pathological examination results and postoperative complications.

\begin{tabular}{ccc}
\hline Pathological examination results & $<8 \%$ weight loss group & $\geq 8 \%$ weight loss group \\
\hline P-Stage I & 2 & 1 \\
II & 5 & 4 \\
III & 5 & 4 \\
IVa & 1 & 0 \\
\hline Postoperative complications & & 9 \\
\hline Hoarseness & 6 & $6 *$ \\
Recurrent nerve paralysis & 0 & $5 *$ \\
Aspiration pneumonia & 1 & 0 \\
Reflux symptoms & 0 & 0 \\
Passage disorder & 1 & 2 \\
Anastomotic leakage & 4 & \\
\hline
\end{tabular}

Values given are the number of patients. ${ }^{*} \mathrm{p}<0.05$ (compared with $<8 \%$ weight loss group value) in chi-square test.

\subsection{Nutrition Evaluation}

When comparing patients' nutrition status according to weight loss rate, there was no significant change in the BMI or body weight between admission and discharge in both groups (Table 3). There was no difference in plasma albumin values before or after surgery between the two groups. A group time repeatedmeasures ANOVA was not significant (Figure 1(a)). Figure 1(b) shows oral intake for the $<8 \%$ weight loss group was $95.5 \% \pm 23.6 \%$ at admission, and $60.2 \%$ $\pm 19.5 \%$ at discharge. On the other hand, the $\geq 8 \%$ weight loss group had an oral intake of $83.9 \% \pm 24.2 \%$ at admission and $73.3 \% \pm 20.5 \%$ at discharge. Only the values on postoperative days were significantly different between the groups $(\mathrm{p}<$ 0.01 ). Figure 2 shows pre- to post-surgery values for each individual and compares the groups in terms of the change scores.

\section{Discussion}

\subsection{Nutrition Evaluation}

Patients with esophageal cancer often have reduced food intake and significant weight loss before surgery because of dysphagia or swallowing problems related to cancer [24] [25]. In this study, the mean BMI at admission was around 22 $\mathrm{kg} / \mathrm{m}^{2}$, and there were no obese patients. Furthermore, after surgery gastric-tube reconstruction of the esophagus reduces its volume capacity and degrades retention function. While a normal stomach has a capacity of about $1000 \mathrm{ml}$, the gastric tube causes a loss of around $300 \mathrm{ml}$, reducing food intake at meals. Therefore, patients can suffer from disrupted nutrition following an esophagectomy [26] [27] [28], and nutrition management is extremely important for the outcome of surgery and patients' postoperative QOL. 

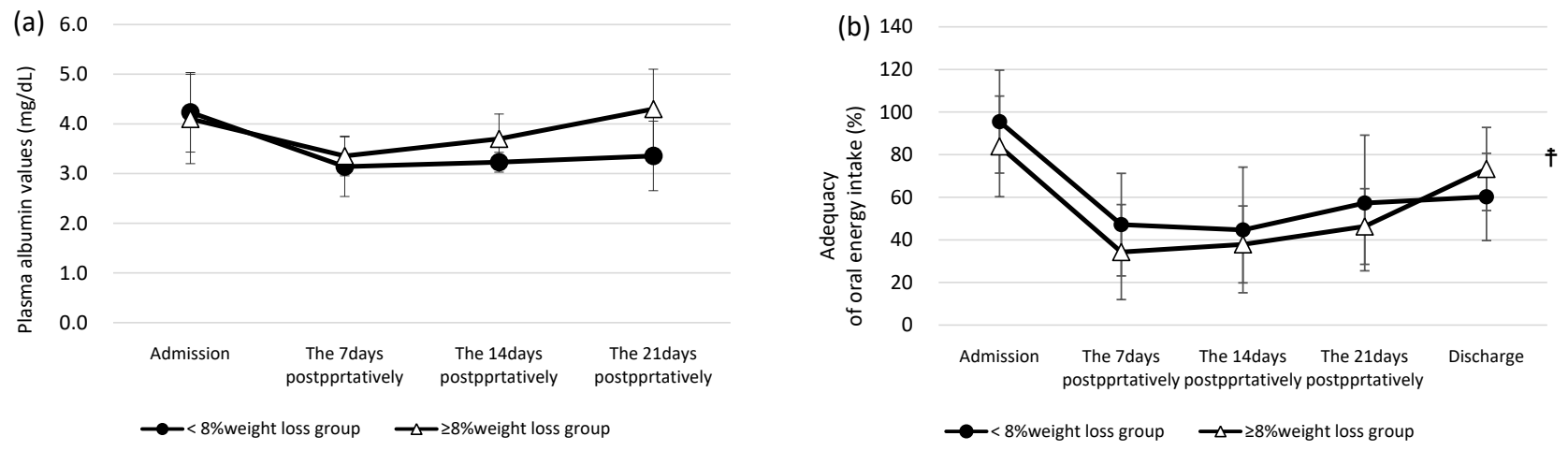

Figure 1. Comparison of Postoperative Plasma Albumin level (a) and adequacy of Oral Energy Intake (b) in $<8 \%$ and $\geq 8 \%$ weight loss groups. Values given as mean (SD). A group time repeated-measures ANOVA was conducted. In addition, a baseline adjusted ANCOVA comparing groups at discharge was used. ${ }^{\star} \mathrm{p}<0.05$ in time repeated-measures ANOVA. $\succcurlyeq$ p $<0.05$ in ANCOVA comparing groups at discharge.
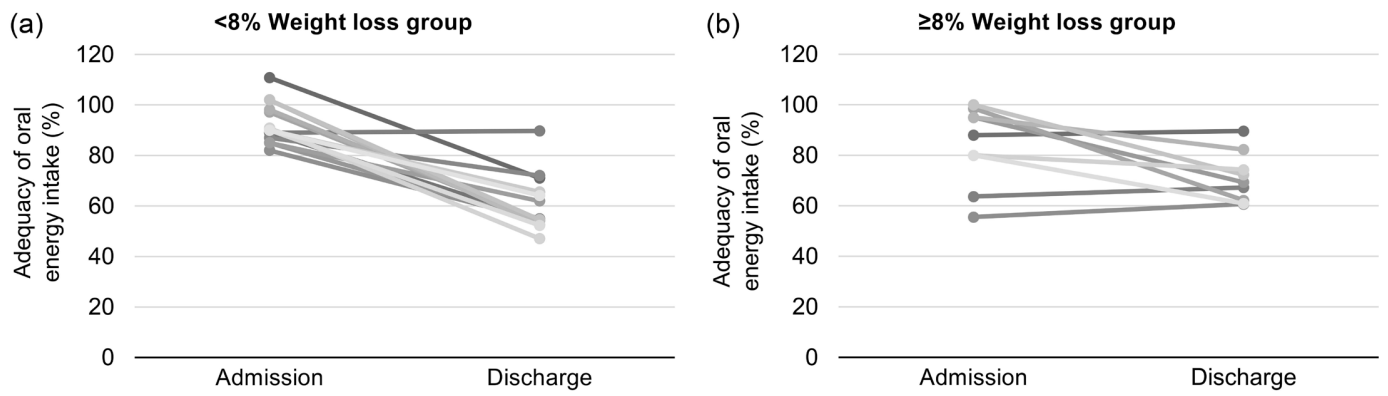

Figure 2. Pre- to Post-surgery Change Scores of Adequacy of Oral Energy Intake for Each Individual. A given pre- to post-surgery change scores of adequacy of oral energy intake for each in $<8 \%$ weight loss groups. B given the scores of adequacy of oral energy intake for each in $\geq 8 \%$ weight loss groups.

Table 3. Comparison of physical status between groups.

\begin{tabular}{ccccc}
\hline \multirow{2}{*}{ Physical Status } & \multicolumn{2}{c}{$<\mathbf{8 \%}$ weight loss group } & \multicolumn{2}{c}{$\mathbf{8} \%$ weight loss group } \\
\cline { 2 - 5 } & Admission & Discharge & Admission & Discharge \\
\hline Rate of weight loss $(\%)$ & & $4.5(2.75)$ & & $10.0(2.62)$ \\
BMI $\left(\mathrm{kg} / \mathrm{m}^{2}\right)$ & $21.6(2.83)$ & $20.6(2.42)$ & $24.3(3.80)$ & $21.9(3.64)$ \\
Body Weight $(\mathrm{kg})$ & $58.5(12.91)$ & $55.7(11.45)$ & $68.6(13.3)$ & $62.2(12.58)$ \\
\hline
\end{tabular}

Rate of weight loss was calculated as the percentage of weight loss at discharge assuming the weight at admission as $100 \%)$. BMI: body mass index. Results are presented as mean (SD).

In this study, there was no difference in albumin levels recorded during hospitalization, but after esophagectomy, energy intake at discharge was insufficient in both groups. Therefore, the weight and BMI at discharge in both groups were lower than at the time of admission. This suggests that weight loss after esophagectomy might be inevitable, and it is important to minimize it. The $\geq 8 \%$ weight loss group had complications of recurrent laryngeal palsy and aspiration pneumonia, which may have prevented adequate ingestion because of dysphagia. However, even in cases with dysphagia, it appeared that nutritional status could 
be maintained with the help of the NST. Finally, as swallowing function determined the type of meal offered, it might have indirectly impacted patient nutrition.

\subsection{Need to Offer Nutrition According to Swallowing Function}

In Japan, the medical remuneration system is revised every 2 years in the context of a universal health insurance system, and NST credit was newly added to the 2010 system [29]. Regarding meal content, guidelines for meals according to swallowing function were established in 2013 [30]. As this study investigated transitional periods, NST intervention and dietary content was left to the judgment of doctors and nurses. In this study, in the case of NST intervention, diet was evaluated by a speech therapist for swallowing function, who provided that information to a dietitian. In the absence of NST intervention, a dietary regimen based on digestive function was provided. The $\geq 8 \%$ weight loss group often experienced recurrent laryngeal palsy and aspiration pneumonia, and required more calories for wound healing. However, NST intervention prevented significant weight loss. Since oral feeding is normally suspended for one-week postsurgery to allow the incision to heal and support overall recovery, the muscles for eating and swallowing are not used and their strength decreases [31]. In addition, even if contrast radiography does not show any abnormalities, because of swallowing muscle fatigue, accidental oral intake may occur while eating [32]. When postoperative feeding begins, feeding and swallowing training is more important than the oral provision of nutrition. Even for patients without recognized eating or swallowing abnormalities, food optimized for post-surgery function reduces the risk of accidental oral intake. Post-esophagectomy eating and swallowing impairments can cause postoperative aspiration pneumonia, a common complication. Impairments happen at the pharyngeal stage, which may be due to post-esophagectomy recurrent nerve palsy as well as pharyngeal constrictor failure and upper esophageal sphincter dysfunction, resulting from esophagectomy and lymph node dissection [33].

Accidental ingestion and aspiration pneumonia are thought to occur when the alimentary bolus enters the trachea due to the tendency of the bolus to remain in the pharynx, and the degradation of the function to transfer the bolus to the esophagus. Accordingly, even if there are pharyngeal stage impairments, such as obstructions, prescribed foods like jelly reduce the risk of accidental oral intake because of its smooth passage through the posterior pharyngeal wall and its easy transfer from the alimentary bolus to the esophagus. Therefore, in the $<8 \%$ weight loss group, aspiration pneumonia may have occurred despite the absence of recurrent laryngeal nerve paralysis, when patients received foods not appropriate to their swallowing function. In addition, at the start of the postoperative diet, eating and swallowing training is more important than oral feeding. Providing a diet that works well with swallowing impairments post-surgery may reduce the risk of aspiration in patients with no evidence of dysphagia. 
In the post-esophagectomy, eating and swallowing impairments can be a cause of postoperative aspiration pneumonia, a common complication of esophagectomy. When observing hoarseness or recurrent nerve palsy, nurses requested NST intervention. If NST support occurred, a diet focused on the swallowing function was provided, which was more effective for the recovery of oral feeding. Therefore, nurses should be required to monitor swallowing ability and function in postoperative dietary care among esophageal cancer patients.

Nurses also monitored the early occurrence of postoperative abnormalities. The value of early detection in monitoring and managing various surgical complications has been demonstrated [34] [35] [36], and postoperative nursing care to restore function is important. In this study, higher risk esophagectomy patients were provided a diet developed by a nurse and NST, tailored to their swallowing function. The appropriate response to dysphagia not only suppressed the occurrence of aspiration pneumonia but also supported patient nutrition. The effectiveness of nurses' dietary care was evaluated based on observation of postoperative nutritional intake and assessment of biochemical data. To meet the necessary energy and nutrient requirements, oral intake combined with gavage and parenteral nutrition were often required. Nurses understood oral intake according to patients' swallowing function and their status of gavage and parenteral nutrition. Patients who required NST intervention based on nurses' observations were those at high risk of aspiration pneumonia. Therefore, NST intervention was deemed appropriate.

\subsection{Limitations}

This study had some limitations. We assumed that the benefits of the oral alimentation applied to all patients. Moreover, our study included a relatively small sample size, which may have confounded the overall conclusions. However, the 22 patients were treated at a single facility by the same surgical and nutrient management teams. Accordingly, patients received uniform treatment, and problems associated with non-uniform treatment in multicenter studies were avoided. Furthermore, our study did not investigate the differences in expected versus actual nutrient intake provided in the hospital during the perioperative period and after discharge. Future studies are needed to examine diet after hospital discharge and compare the oral intake between groups at the 6th or 12th month, postoperatively.

\section{Conclusion}

A weight loss $\geq 8 \%$ may be facilitated, or at least confounded, by the presence of recurrent nerve paralysis and aspiration pneumonia. When weight loss was significant, nurses provided oral intake support with the NST, and patients maintained oral intake levels similar to the group with weight loss under $8 \%$. Finally, nurses efficiently identified the need to observe recurrent laryngeal nerve palsy and aspiration pneumonia in conjunction with nutritional assessment to en- 
hance physical recovery in undernourished patients. Our study did not investigate the differences in the expected versus actual nutrient intakes provided in the hospital during the perioperative period and those after discharge. In a future study, we believe it would be interesting to consider a diet survey after hospital discharge and compare the oral intake between study groups at the sixth or twelfth month postoperatively.

\section{Acknowledgements}

This research was supported by JSPS KAKENHI Grant-in-Aid for Young Scientists (B) (Number 16K20744). The authors are grateful to S. Kumagai, M. Tsutsumi, T. Shichinohe, and the nursing staff for their constructive comments and warm encouragement.

\section{Conflicts of Interest}

The authors declare no conflicts of interest regarding the publication of this paper.

\section{References}

[1] Matsuda, T., Marugame, T., Kamo, K., Katanoda, K., Ajiki, W., Sobue, T. and Japan Cancer Surveillance Research Group (2011) Cancer Incidence and Incidence Rates in Japan in 2005: Based on Data from 15 Population-Based Cancer Registries in the Monitoring of Cancer Incidence in Japan (MCIJ) Project. Japanese Journal of Clinical Oncology, 42, 139-147. https://doi.org/10.1093/jico/hyr184

[2] International Agency for Research on Cancer, World Health Organization (2021, July 15). The Global Cancer Observatory. http://gco.iarc.fr

[3] Wilmore, D.W. and Kehlet, H. (2001) Management of Patients in Fast Track Surgery. BMJ, 322, 473-476. https://doi.org/10.1136/bmj.322.7284.473

[4] Fearon, K.C., Ljungqvist, O., Von Meyenfeldt, M., Revhaug, A., Dejong, C.H., Lassen, K., Nygrenb, J., Hausel, J., Soop, M., Andersen, J. and Kehlet, H. (2005) Enhanced Recovery after Surgery: A Consensus Review of Clinical Care for Patients Undergoing Clinic Resection. Clinical Nutrition, 24, 466-477. https://doi.org/10.1016/j.clnu.2005.02.002

[5] Sinha, U.K., Swanson, M.S., Villegas, B.C., Ouyoung, L.M. and Kokot, N. (2019) Outcomes of Self-Esophageal Dilation for Head and Neck Cancer Patients. American Journal of Speech-Language Pathology, 28, 1060-1066. https://doi.org/10.1044/2019 AJSLP-18-0190

[6] Kight, C.E. (2008) Nutrition Considerations in Esophagectomy Patients. Nutrition in Clinical Practice, 23, 521-528. https://doi.org/10.1177/0884533608323427

[7] Goense, L., van Dijk, W.A., Govaert, J.A., van Rossum, P.S., Ruurda, J.P. and van Hillegersberg, R. (2017) Hospital Costs of Complications after Esophagectomy for Cancer. European Journal of Surgical Oncology, 43, 696-702. https://doi.org/10.1016/j.ejso.2016.11.013

[8] Nakahara, Y., Yamasaki, M., Miyazaki, Y, Tanaka, K, Makino, T, Takahashi, T, Kurokawa, Y., Nakajima, K., Takiguchi, S., Mori, M. and Doki, Y. (2018) Reflux after Esophagectomy with Gastric Conduit Reconstruction in the Posterior Mediastinum for Esophageal Cancer: Original Questionnaire and EORTC QLQ-C30 Survey. Dis- 
eases of the Esophagus, 31, 1-7. https://doi.org/10.1093/dote/doy001

[9] Okada, G., Momoki, C., Habu, D., Kambara, C., Fujii, T., Matsuda, Y., Lee, S. and Osugi, H. (2019) Effect of Postoperative Oral Intake on Prognosis for Esophageal Cancer. Nutrients, 11, 1338. https://doi.org/10.3390/nu11061338

[10] McClave, S.A., Taylor, B.E., Martindale, R.G., Malissa, M.M., Debbie, R.J., Carol, B., Mary, S.M., Evangelia, D., Todd, W.R., Gail, A.C., Jane, M.G., Gordon, S.S., Pamela, R.R. and Charlene, C. (2016) Guidelines for the Provision and Assessment of Nutrition Support Therapy in the Adult Critically Ill Patient. Journal of Parenteral and Enteral Nutrition, 40, 159-211. https://doi.org/10.1177/0148607115621863

[11] Singer, P., Berger, M.M., Van den Berghe, G., Biolo, G., Calder, P., Forbes, A., Griffiths, R., Kreyman, G., Leverve, X., Pichard, C. and Pichard, C. (2009) ESPEN Guidelines on Parenteral Nutrition: Intensive Care. Clinical Nutrition, 28, 387-400. https://doi.org/10.1016/j.clnu.2009.04.024

[12] Zheng, Y., Li, Y., Wang, Z., Sun, H. and Zhang, R.A. (2015) A Video Demonstration of the Li's Anastomosis-The Key Part of the "Non-Tube No Fasting" Fast Track Program for Resectable Esophageal Carcinoma. Journal of Thoracic Disease, 7, 1264-1268.

[13] Zhu, Z., Li, Y., Zheng, Y., Sun, H., Liu, X., Zhang, R., Wang, Z., Liu, S., Chen, X., Hua, X., Yu, Y., Li, H., Zhang, J. and Liu, Q. (2018) Chewing 50 Times per Bite Could Help to Resume Oral Feeding on the First Postoperative Day Following Minimally Invasive Oesophagectomy. European Journal of Cardio-Thoracic Surgery, 53, 325-330. https://doi.org/10.1093/ejcts/ezx291

[14] Nederkoorn, C., Smulders, F.T.Y. and Jansen, A. (2000) Cephalic Phase Responses, Craving and Food Intake in Normal Subjects. Appetite, 35, 45-55.

https://doi.org/10.1006/appe.2000.0328

[15] Smeets, P.A.M., Erkner, A. and de Graaf, C. (2010) Cephalic Phase Responses and Appetite. Nutrition Reviews, 68, 643-655. https://doi.org/10.1111/j.1753-4887.2010.00334.x

[16] Kumai, Y., Samejima, Y., Watanabe, M. and Yumoto, E. (2016) Videofluoroscopic Evaluation of Pharyngeal Swallowing Dysfunction after Esophagectomy with ThreeField Lymph Node Dissection. European Archives of Oto-Rhino-Laryngology, 274, 321-326. https://doi.org/10.1007/s00405-016-4209-9

[17] Fujita, T., Iida, Y., Tanaka, C., Nakamura, K., Yamanaka, K., Ueno, J., Iino, Y., Chitose, H., Sakamoto, H. and Daiko, H. (2017) Development and Evaluation of an "Interdisciplinary Postoperative Support Program" in Outpatient Clinics after Thoracic Esophagectomy. International Journal of Surgery, 43, 58-66. https://doi.org/10.1016/j.ijsu.2017.05.036

[18] Baker, M., Halliday, V., Williams, R.N. and Bowrey, D.J. (2015) A Systematic Review of the Nutritional Consequences of Esophagectomy. Clinical Nutrition, 35, $987-$ 994. https://doi.org/10.1016/j.clnu.2015.08.010

[19] Collard, J.M., Tinton, N., Malaise, J., Romagnoli, R., Otte, J.B. and Kestens, P.J. (1995) Esophageal Replacement: Gastric Tube or Whole Stomach? The Annals of Thoracic Surgery, 60, 261-266. https://doi.org/10.1016/0003-4975(95)00411-D

[20] Gawad, K.A., Hosch, S.B., Bumann, D., Lübeck, M., Moneke, L.C., Bloechle, C., Knoefel, W., Busch, C., Küchler, Th. and Izbicki, J. (1999) How Important Is the Route of Reconstruction after Esophagectomy: A Prospective Randomized Study. American Journal of Gastroenterology, 94, 1490-1496. https://doi.org/10.1111/j.1572-0241.1999.01131.x

[21] Brown, A., Taylor, A., Mitchell, K., Veeramootoo, D. and Wajed, S.A. (2008) Nutri- 
tional Advantage for Patients Undergoing Minimally Invasive Surgical Resection for Oesophago-Gastric Cancer. e-SPEN Journal, 8, e51-e54.

https://doi.org/10.1016/j.clnme.2012.12.004

[22] Haverkort, E.B., Binnekade, J.M., Busch, O.R., van Berge Henegouwen, M.I., de Haan, R.J. and Gouma, D.J. (2010) Presence and Persistence of Nutrition-Related Symptoms during the First Year Following Esophagectomy with Gastric Tube Reconstruction in Clinically Disease-Free Patients. World Journal of Surgery, 34, 2844 2852. https://doi.org/10.1007/s00268-010-0786-8

[23] Ryan, A.M., Rowley, S.P., Healy, L.A., Flood, P.M., Ravi, N. and Reynolds, J.V. (2006) Post-Oesophagectomy Early Enteral Nutrition via a Needle Catheter Jejunostomy: 8-Year Experience at a Specialist Unit. Clinical Nutrition, 25, 386-393. https://doi.org/10.1016/j.clnu.2005.12.003

[24] Fukuda, H., Yamashita, A., Imai, T., Tshumaki, H., Nagata, N., Ishikawa, H., Niihara, M., Tsubosa, Y. and Onozaaw, Y. (2019) Preventive Effect of Nutrition Support on Peroneal Neuropathy in Cancer Patients. Frontiers in Nutrition, 5, Article No. 139. https://doi.org/10.3389/fnut.2018.00139

[25] Steenhagen, E., van Vulpen, J.K., van Hillegersberg, R., May, A.M. and Siersema, P.D. (2017) Nutrition in Peri-Operative Esophageal Cancer Management. Expert Review of Gastroenterology \& Hepatology, 11, 663-672. https://doi.org/10.1080/17474124.2017.1325320

[26] Andreyev, H.J.N., Norman, A.R., Oates, J. and Cunningham, D. (1998) Why Do Patients with Weight Loss Have a Worse Outcome When Undergoing Chemotherapy for Gastrointestinal Malignancies? European Journal of Cancer, 34, 503-509. https://doi.org/10.1016/S0959-8049(97)10090-9

[27] Dewys, W.D., Begg, C., Lavin, P.T., Band, P.R., Bennett, J.M., Bertino, J.R., Cohen, M.H., Douglass Jr., H.O., Engstrom, P.F., Ezdinli, E.Z., Horton, J., Johnson, G.J., Moertel, C.G., Oken, M.M., Perlia, C., Rosenbaum, C., Silverstein, M.N., Skeel, R.T., Sponzo, R.W. and Tormey, D.C. (1980) Prognostic Effect of Weight Loss Prior to Chemotherapy in Cancer Patients. Eastern Cooperative Oncology Group. The American Journal of Medicine, 69, 491-497. https://doi.org/10.1016/S0149-2918(05)80001-3

[28] Momosaki, R., Abo, M., Kakuda, W. and Kobayashi, K. (2013) Applicability of the Two-Step Thickened Water Test in Patients with Poststroke Dysphagia: A Novel Assessment Tool for Paste Food Aspiration. Journal of Stroke and Cerebrovascular Diseases, 22, 817-821. https://doi.org/10.1016/j.jstrokecerebrovasdis.2012.05.011

[29] Higashiguchi, T. (2016) Effectiveness of Nutrition Support Teams and Future Outlook in an Aging Society. Official Journal of the Japan Surgical Society, 117, 204-211. (In Japanese)

[30] Watanabe, E., Yamagata, Y., Fujitani, J., Fujishima, I., Takahashi, K., Uyama, R., Ogoshi, H., Kojo, A., Maeda, H., Ueda, K. and Kayashita, J. (2018) The Criteria of Thickened Liquid for Dysphagia Management in Japan. Dysphagia, 33, 26-32. https://doi.org/10.1007/s00455-017-9827-x

[31] Baba, M., Natsugoe, S., Shimada, M., Nakano, S., Noguchi, Y., Kawaguchi, K., Kusano, C. and Aikou, T. (1999) Does Hoarseness of Voice from Recurrent Nerve Paralysis after Esophagectomy for Carcinoma Influence Patient Quality of Life? Journal of the American College of Surgeons, 188, 231-236. https://doi.org/10.1016/S1072-7515(98)00295-6

[32] Kumai, Y., Yoshida, N., Kamenosono, Y., Matsubara, K., Samejima, Y., Baba, H. and Yumoto, E. (2017) Effects of Chin-Down Maneuver on the Parameters of Swallowing Function after Esophagectomy with 3-Field Lymphadenectomy Examined 
by Videofluoroscopy. Archives of Physical Medicine and Rehabilitation, 98, 11741179. https://doi.org/10.1016/j.apmr.2016.11.005

[33] Shiraishi, O., Kato, H., Iwama, M., Hiraki, Y., Yasuda, A., Peng, Y.F., Shinkai, M., Kimura, Y., Imano, M. and Yasuda, T. (2019) Simplified Percutaneous Endoscopic Transgastric Conduit Feeding Jejunostomy for Dysphagia after Esophagectomy. Diseases of Esophagus, 28, 1060-1066. https://doi.org/10.1093/dote/doz042

[34] Jesse, M. (2017) Occurrence of Peroneal Neuropathy in Oncology Patients: A Systematic Review. Rehabilitation Oncology, 35, 181-187. https://doi.org/10.1097/01.REO.0000000000000082

[35] Koehler, P.J., Buscher, M., Rozeman, C.A.M., Leffers, P. and Twijnstra, A. (1997) Peroneal Nerve Neuropathy in Cancer Patients: A Paraneoplastic Syndrome? Journal of Neurology, 244, 328-332. https://doi.org/10.1007/s004150050096

[36] Rubin, D.I., Kimmel, D.W. and Cascino, T.L. (1998) Outcome of Peroneal Neuropathies in Patients with Systemic Malignant Disease. Cancer, 83, 1602-1606. https://doi.org/10.1002/(SICI)1097-0142(19981015)83:8<1602::AID-CNCR15>3.0.C O;2-N 